\title{
Penentuan Rute Evakuasi Bencana Kebakaran Menggunakan Algoritma Dijkstra berbasis Web Framework Vue.js
}

\author{
I Gede Surya Rahayuda ${ }^{1}$, Ni Putu Linda Santiari ${ }^{2}$ \\ Institut Teknologi dan Bisnis STIKOM Bali \\ e-mail: ${ }^{1}$ surya_rahayuda@stikom-bali.ac.id, ${ }^{2}$ linda_santiari@stikom-bali.ac.id \\ Diajukan: 25 November 2019; Direvisi: 23 Desember 2019; Diterima: 27 April 2020
}

\begin{abstract}
Abstrak
Penentuan rute terdekat diperlukan pada setiap perjalanan. Pada penelitian sebelumnya penulis telah menggunakan beberapa metode pencarian jalur yang diterapkan untuk menentukan jalur terdekat pengiriman produk. Pada penelitian saat ini penulis menerapkan metode pencarian jalur untuk penentuan rute terdekat perjalanan tim pemadam kebakaran. Diharapkan dengan digunakannya metode tersebut dapat mempercepat penentuan rute terdekat menuju lokasi kebakaran. Metode pencarian jalur yang digunakan adalah metode Dijkstra, metode tersebut diimplementasikan berbasis web framework vue.js. Berdasarkan penelitian yang dilakukan pada beberapa data tes, metode Dijkstra berhasil menentukan rute evakuasi terbaik. Penulis memilih menggunakan framework vue.js sebagai front-end web karena vue.js memiliki kelebihan dari desain tampilan yang baik dan reaktif. Berdasarkan pengujian sistem menggunakan black-box testing terhadap berbagai proses yang ada didapatkan hasil yang baik dan sesuai keinginan.
\end{abstract}

Kata kunci: Sistem Informasi Evakuasi Bencana, Dijkstra, Vue.js, Vuetify.js.

\begin{abstract}
Determination of the closest route is required on each trip. In previous studies the author has used several path search methods that are applied to determine the closest path of product delivery. In the current study the authors applied the path search method to determine the closest route to the fire fighter team. It is hoped that the use of these methods can accelerate the determination of the nearest route to the fire location. The path search method used is the Dijkstra method, the method is implemented based on the web framework vue.js. Based on research conducted on several test data, Dijkstra's method succeeded in determining the best evacuation route. The author chose to use the vue.js framework as a web front-end because vue.js has the advantages of good and reactive display design. Based on system testing using blackbox testing on various existing processes obtained good results and as desired.
\end{abstract}

Keywords: Emergency Response System, Dijkstra, Vue.js, Vuetify.js.

\section{Pendahuluan}

Penentuan jalur terbaik atau sering disebut dengan shortest pathfinding merupakan suatu metode yang memiliki banyak manfaat dan dapat diterapkan pada berbagai kasus dan bidang ilmu. Pada penelitian sebelumnya penulis telah mengembangkan suatu program desktop menggunakan bahasa pemrograman Visual Basic, di mana program tersebut telah berhasil menentukan rute terbaik pada kasus pengiriman produk.

Pada tahun pertama program dikembangkan menggunakan dua metode, yaitu metode Iterative Deepening Search dan metode Held-Karp. Dari hasil penelitian yang dilakukan diketahui bahwa metode Held-Karp mendapatkan hasil yang lebih baik dibandingkan dengan metode Iterative Deepening Search [1]. Dalam beberapa pengiriman produk terdapat hasil yang sama dari kedua metode. Namun secara keseluruhan metode Held-Karp mendapatkan hasil yang lebih baik, selisih perbedaan antara kedua metode adalah sebesar $19,66 \%$ [2][3].

Pada tahun kedua, penulis menambahkan dua metode yaitu, Bidirectional Search dan Depth Limited Search. Metode tersebut berhasil diterapkan pada program dan digunakan untuk menentukan rute terpendek pada beberapa data tes. Dari perbandingan dengan metode lainnya, metode Bidirectional Search dan Depth Limited Search mendapatkan beberapa hasil yang lebih baik dari metode lainnya [4]. Menurut penulis metode Bidirectional Search akan lebih baik jika diterapkan pada kasus yang tidak memerlukan 
perjalanan kembali ke titik awal dan akan mendapatkan hasil optimal jika digunakan pada kasus pengiriman yang memiliki data titik dengan jarak berdekatan di level awal dan akhir grap matrik, dan memiliki titik yang berjauhan di level tengah dari grap matrik. Metode Depth Limited Search baik diterapkan pada beberapa pengiriman produk yang memiliki poin atau tempat pengiriman yang banyak dan perlu dibatasi pada kegiatan pengiriman yang berbeda. Dari hasil yang didapatkan metode Depth Limited Search memiliki kesamaan dengan metode Iterative Deepening Search, hal ini disebabkan karena kedua metode tersebut merupakan pengembangan dari metode Depth First Search. Berdasarkan perbandingan hasil yang didapatkan, jika semua metode tersebut dibandingkan maka metode Held-Karp mendapatkan hasil yang terbaik [5].

Pada penelitian saat ini, atau penelitian tahun ketiga, penulis akan menggunakan metode Dijkstra, berdasarkan beberapa uji coba yang pernah dilakukan, metode Dijkstra memiliki kemungkinan untuk mendapatkan rute hasil yang lebih baik, dibandingkan dengan metode Held-Karp. Berbeda dengan penelitian sebelumnya, di mana metode shortest pathfinding diterapkan pada kasus pengiriman produk, pada penelitian tahun ini, penulis akan mencoba menerapkan metode Dijkstra pada suatu kasus penelitian mengenai penentuan rute terbaik tim pemadam kebakaran saat melakukan evakuasi korban pada bencana kebakaran. Sesuai dengan perencanaan pada penelitian sebelumnya [6][7], pada tahun ini penulis akan mengembangkan kedua metode tersebut menggunakan web framework. Dari beberapa web framework yang ada, penulis memilih menggunakan web framework Vue.js, karena framework Vue.js, memiliki kelebihan dari segi tampilan desain, Vue merupakan frontend framework yang menduduki peringkat atas dari beberapa situs top rank framework web saat ini. Vue memiliki kelebihan pada proses yang reactive, di mana hasil dari proses dilakukan secara langsung, seperti ketika berpindah halaman, browser tidak lagi me-reload seluruh elemen halaman, dengan begitu akan didapatkan response yang lebih cepat, browser juga tidak perlu mengunduh ulang elemen-elemen yang sudah ada, dengan begitu pengguna dapat lebih menghemat bandwith [8]. Fasilitas two way data binding dapat memberikan hasil langsung saat teks tersebut diubah, hal ini memungkinkan pengguna dapat memberikan pesan kepada pengguna lainnya tanpa jeda reload atau save. Vue juga menyediakan fasilitas drag and drop yang memungkinkan sebuah kelompok post bisa dipindahkan ke tempat lainnya secara real time. Ada lebih banyak lagi kelebihan dari Vue.js, dengan beberapa kelebihan tersebut, penulis akan menggunakan framework Vue.js pada penelitian tahun ini [9][10]. Penulis berharap nantinya akan dihasilkan suatu implementasi program yang baik, dan dapat memberikan beberapa pengetahuan baru bagi penulis, pembaca dan ilmu pengetahuan.

\section{Metode Penelitian}

Penulis menggunakan metode penelitian SDLC (System Development Life Cycle), SDLC merupakan siklus pengembangan perangkat lunak yang terdiri dari beberapa tahapan. Terdapat 4 metodologi dalam pengembangan perangkat lunak SDLC, yaitu: Waterfall, Prototype, RAD (Rapid Application Development), dan Agile Software Development. Pada penelitian ini penulis menggunakan metode SDLC Waterfall. Waterfall atau Classic Life Cycle merupakan metode yang banyak digunakan pada Software Enginering, metode ini melakukan pendekatan secara sistematis dan terurut dari level kebutuhan sistem lalu menuju ke tahap analisis, desain, implementasi, dan pengujian sistem. Disebut Waterfall karena tahap demi tahap yang dilalui harus menunggu selesainya tahap sebelumnya dan berjalan berurutan. Adapun tahapan-tahapan pada penelitian ini adalah:

a. Pengumpulan Data

Tahapan ini dilakukan untuk memperoleh data yang diperlukan dalam pengembangan sistem. Pengumpulan data dilakukan dengan mengambil data secara online dari situs Pemadam Kebakaran pada sebuah kota di negara Amerika Serikat, dengan nama Napperville. Data tersebut berupa data bencana kebakaran dari awal tahun 2019 sampai saat ini. Selain mengakses data secara online, penulis juga mengumpulkan data menggunakan studi literatur seperti buku, jurnal, prosiding, internet, dan beberapa sumber lainnya yang berkaitan dengan penelitian yang dilakukan.

b. Analisis

Tahapan analisis dilakukan untuk menganalisis permasalahan dan menentukan kebutuhan yang diperlukan dalam pembuatan sistem. Hasil analisis tersebut kemudian dijadikan dasar dalam membuat perancangan desain sistem.

c. Desain

Tahapan desain dilakukan untuk mengetahui alur data dan proses yang terjadi sistem. Perancangan desain sistem dilakukan menggunakan Data Flow Diagram (DFD).

Penentuan Rute Evakuasi Bencana Kebakaran Menggunakan Algoritma Dijkstra berbasis Web

Framework Vue.js (I Gede Surya Rahayuda) 
d. Implementasi Sistem

Tahapan implementasi dilakukan untuk menerjemahkan desain yang telah dibuat menggunakan bahasa pemrograman agar dapat dikembangkan menjadi sebuah sistem atau perangkat lunak. Sistem akan dikembangkan berbasis web menggunakan framework Vue.js. Untuk pencarian rute terdekat digunakan metode Dijkstra.

e. Pengujian Sistem

Tahapan pengujian sistem dilakukan untuk mengetahui apakah sistem yang dibuat telah sesuai dengan tujuan yang direncanakan. Pengujian sistem dilakukan menggunakan metode black-box testing.

Berikut merupakan gambar ilustrasi dari metode penelitian yang dilakukan:

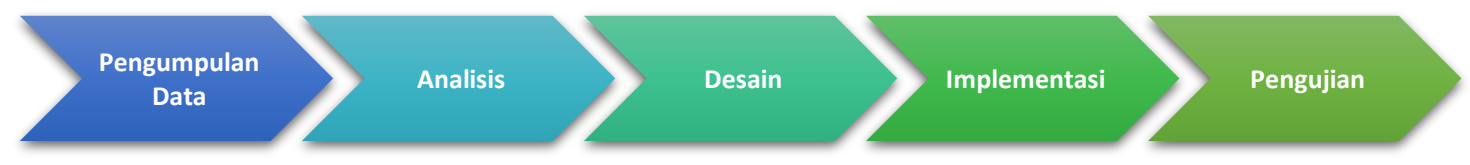

Gambar 1. Metode penelitian.

\section{Hasil dan Pembahasan}

\subsection{Pengumpulan Data}

Berikut adalah beberapa data yang akan digunakan pada penelitian. Data tersebut merupakan open data set yang dibagikan oleh pemerintah Amerika Serikat, lebih khususnya pada sebuah kota dengan nama Napperville [13]. Berdasarkan sumbernya jenis data yang digunakan adalah data sekunder, karena data yang dikumpulkan diperoleh dari open data set online: https://data.naperville.il.us. Data tersebut merupakan data resmi yang dibagikan oleh departemen pemadam kebakaran pada sebuah kota di Amerika Serikat, yaitu Napperville Fire Departement [14][12]. Sampai saat ini telah tercatat sebanyak 149.864 kejadian bencana kebakaran yang terjadi pada kota tersebut dari tahun 2010 - 2019. Penulis menggunakan sebanyak 80 data set terbaru dari keseluruhan data tersebut, berikut adalah beberapa data set yang akan digunakan pada penelitian, terlihat pada Tabel 1.

Tabel 1. Data bencana kebakaran dan koordinat pada map.

\begin{tabular}{clllc}
\hline No & Tanggal & \multicolumn{1}{c}{ Alamat } & Kota & Koordinat \\
\hline 1 & 22-Apr-2019 & Normandy & Naperville & $(41.711936,-88.222768)$ \\
\hline 2 & $22-A p r-2019$ & Audubon & Naperville & $(41.811179,-88.200837)$ \\
\hline 3 & $22-A p r-2019$ & Rosecroft & Naperville & $(41.711787,-88.210966)$ \\
\hline 4 & $22-A p r-2019$ & Naperville Wheaton & Naperville & $(41.799269,-88.122684)$ \\
\hline 5 & $22-A p r-2019$ & Bradford & Naperville & $(41.785456,-88.206206)$ \\
\hline 6 & $22-A p r-2019$ & Royal St George & Naperville & $(41.781942,-88.168579)$ \\
\hline 7 & $22-A p r-2019$ & Water & Naperville & $(41.770828,-88.150572)$ \\
\hline 8 & $22-A p r-2019$ & Hidden Spring & Naperville & $(41.777714,-88.170752)$ \\
\hline 9 & $22-A p r-2019$ & Bradford & Naperville & $(41.785456,-88.206206)$ \\
\hline 10 & $22-A p r-2019$ & Oswego & Naperville & $(41.758973,-88.18478)$ \\
\hline 11 & $21-A p r-2019$ & Ogden & Naperville & $(41.783567,-88.173161)$ \\
\hline 12 & $21-A p r-2019$ & Flat Rock & Naperville & $(41.685055,-88.193387)$ \\
\hline 13 & $21-A p r-2019$ & Naper & Naperville & $(41.803009,-88.119643)$ \\
\hline 14 & $21-A p r-2019$ & Timber Creek & Naperville & $(41.704287,-88.155835)$ \\
\hline 15 & $21-A p r-2019$ & Grommon & Naperville & $(41.699184,-88.178725)$ \\
\hline 16 & $21-A p r-2019$ & Fulham & Naperville & $(41.727057,-88.203123)$ \\
\hline 17 & $21-A p r-2019$ & Diehl & Naperville & $(41.798941,-88.22491)$ \\
\hline 18 & $21-A p r-2019$ & Iroquois & Naperville & $(41.797784,-88.127581)$ \\
\hline 19 & $21-A p r-2019$ & Main & Naperville & $(41.774669,-88.149323)$ \\
\hline 20 & $21-A p r-2019$ & Ogden & Naperville & $(41.788615,-88.132897)$ \\
\hline 50 & $\ldots$ & $\ldots$ & N & $\ldots$ \\
\hline 80 & $15-A p r-2019$ & Crystal & Naperville & $(41.798796,-88.191144)$ \\
\hline
\end{tabular}

\subsection{Analisis dan Desain Sistem}

Untuk menjelaskan alur dan konsep dari penelitian, penulisan menggunakan Data Flow Diagram (DFD) untuk memodelkan alur penelitian yang dilakukan. DFD digambarkan mulai dari diagram konteks sampai dengan level 2. Pada DFD level 1 dan selanjutnya, penulis membatasi pengembangan DFD hanya 
pada proses Dijkstra untuk mempersingkat penggambaran model DFD dan untuk memfokuskan pada inti dari penelitian yang dilakukan. DFD dari Sistem Informasi dapat dilihat pada gambar.

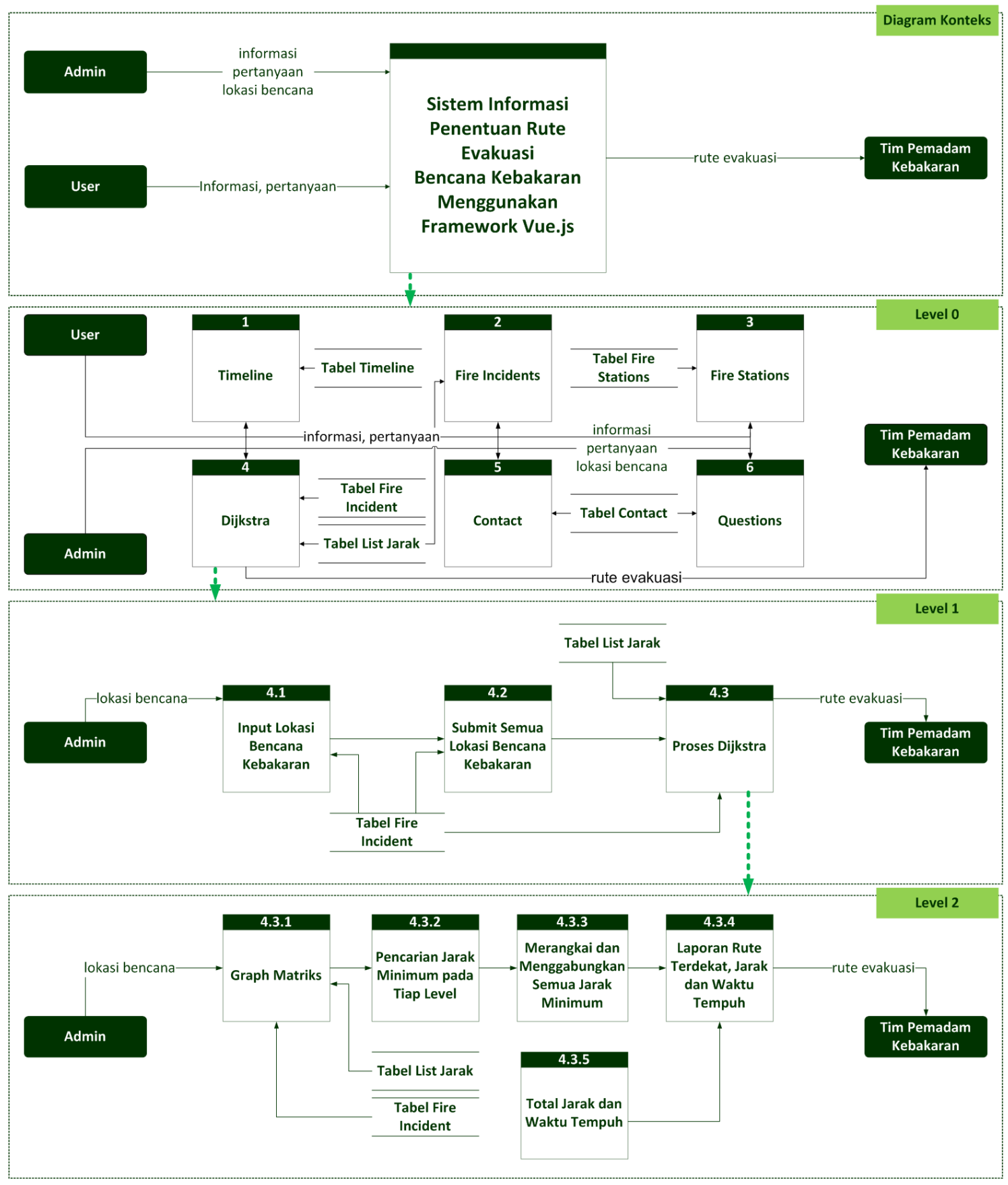

Gambar 2. Data flow diagram. 


\subsection{Implementasi}

Metode Dijkstra telah berhasil dikembangkan berbasis web framework Vue.js. Website tersebut telah diunggah secara online pada salah satu web hosting dan dapat diakses melalui url: http://suryarahayuda.phpnet.us/rute-evakuasi. Selain metode Dijkstra juga ditambahkan beberapa halaman lain sebagai pelengkap dari sistem informasi evakuasi bencana kebakaran. Beberapa halaman tersebut adalah: Home, Fire Incident, Fire Stations, Contact Us, dan Questions. Halaman Dijkstra dibangun untuk menerapkan metode Dijkstra. Pada halaman ini user atau admin dapat memilih beberapa lokasi kejadian kebakaran secara acak, dan kemudian menekan tombol Shortest Path. Sistem akan mengarahkan semua data yang diinput-kan menuju halaman matrik.php dan dijkstra.php di mana pada halaman tersebut data akan diproses menggunakan graph matrik dan metode Dijkstra. Akan terlihat graph matrik yang dihasilkan, jarak terdekat pada tiap level matrik dan rangkaian gabungan jalur terdekat yang terbentuk.

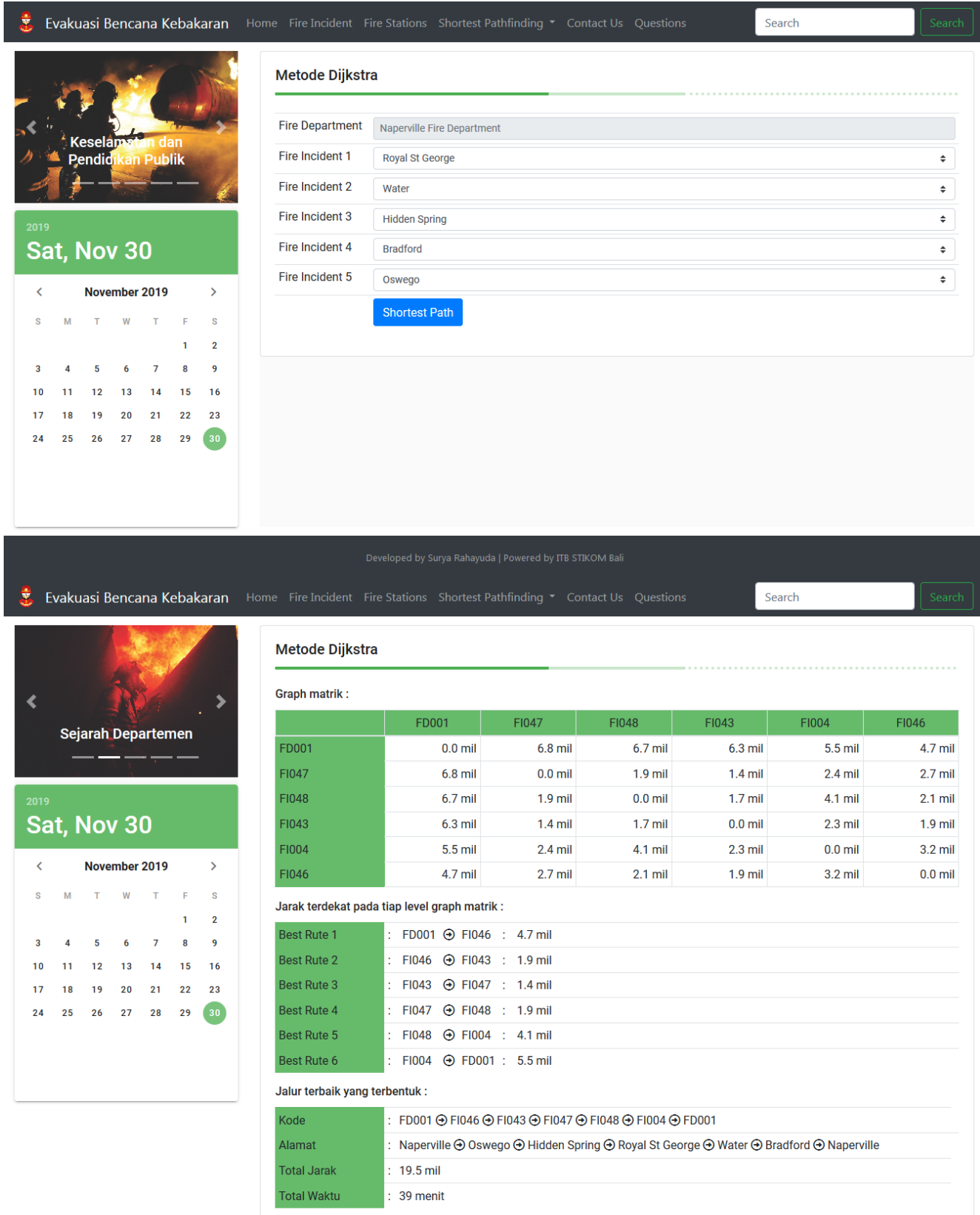

Developed by Surya Rahayuda | Powered by пr strкoм Bali

Gambar 3. Halaman Metode Dijkstra. 
Metode Dijkstra mengawali pencarian dari level pertama grafik matrik, seperti terlihat pada grafik matrik level pertama di bawah ini:

\begin{tabular}{ccccccc}
\hline 1 & FD001 & FI047 & FI048 & FI043 & FI004 & FI046 \\
\hline FD001 & 0.0 & 6.8 & 6.7 & 6.3 & 5.5 & 4.7 \\
\hline
\end{tabular}

dari keseluruhan data yang terdapat pada grafik level pertama, ditemukan bahwa rute terdekat adalah FD001 menuju FI046 dengan jarak 4.7 mil. Kemudian dilanjutkan dengan pencarian pada grafik matrik pada level FI046:

\begin{tabular}{ccccccc}
\hline 2 & FD001 & FI047 & FI048 & FI043 & FI004 & FI046 \\
\hline FD046 & 4.7 & 2.7 & 2.1 & 1.9 & 3.2 & 0.0 \\
\hline
\end{tabular}

pada level grafik tersebut, ditemukan FI046 menuju FI043 memiliki rute terdekat sebesar 1.9 mil, pencarian dilanjutkan pada grafik level FI047:

\begin{tabular}{ccccccc}
\hline 3 & FD001 & FI047 & FI048 & FI043 & FI004 & FI046 \\
\hline FD043 & 6.3 & 1.4 & 1.7 & 0.0 & 2.3 & 1.9 \\
\hline
\end{tabular}

pada level grafik di atas, ditemukan rute terdekat adalah FI043 menuju FI047 sebesar 1.4 mil, pencarian dilanjutkan pada grafik level FI047:

\begin{tabular}{ccccccc}
\hline 4 & FD001 & FI047 & FI048 & FI043 & FI004 & FI046 \\
\hline FD047 & 6.0 & 0.0 & 1.9 & 1.4 & 2.4 & 2.7 \\
\hline
\end{tabular}

ditemukan rute terdekat adalah FI047 menuju FI048 sebesar 1.9 mil, pencarian dilanjutkan pada grafik level FI048:

\begin{tabular}{ccccccc}
\hline 5 & FD001 & FI047 & FI048 & FI043 & FI004 & FI046 \\
\hline FD048 & 6.7 & 1.9 & 0.0 & 1.7 & 4.1 & 2.1 \\
\hline
\end{tabular}

rute terdekat ditemukan pada FI048 menuju FI004 sebesar 4.1 mil, pencarian dilanjutkan pada grafik level FI004:

\begin{tabular}{ccccccc}
\hline 6 & FD001 & FI047 & FI048 & FI043 & FI004 & FI046 \\
\hline FD004 & 5.5 & 2.4 & 4.1 & 2.3 & 0.0 & 3.2 \\
\hline
\end{tabular}

grafik telah mencapai level akhir, pada level tersebut rute yang dipilih adalah rute kembali ke poin awal, yaitu FD004 menuju FD001, sebesar 5.5 mil. Semua rute tersebut kemudian digabungkan menjadi rangkaian rute perjalanan: FD001 $\rightarrow$ FI046 $\rightarrow$ FI043 $\rightarrow$ FI047 $\rightarrow$ FI048 $\rightarrow$ FI0204 $\rightarrow$ FD001, dengan total jarak tempuh sejauh 19.5 mil dan waktu tempuh selama 39 menit [14][13].

Semua data tes yang telah dikumpulkan dan disimpan kemudian diuji coba pada program berbasis web. Dari uji coba yang dilakukan dapat dihasilkan rute evakuasi pada tiap kasus bencana kebakaran, seperti terlihat pada Tabel 2 .

Tabel 2. Hasil uji coba pada beberapa data tes.

\begin{tabular}{|c|c|c|}
\hline Rute Hasil & Jarak & Waktu \\
\hline Kasus 1, Kejadian Kebakaran pada : 22 April 2019 & & \\
\hline Naperville F.D. $\rightarrow$ Oswego & $4.7 \mathrm{mil}$ & 9.4 menit \\
\hline Oswego $\rightarrow$ Hidden Spring & $1.9 \mathrm{mil}$ & 3.8 menit \\
\hline Hidden Spring $\rightarrow$ Royal St George & $1.4 \mathrm{mil}$ & 2.8 menit \\
\hline Royal St George $\rightarrow$ Water & $1.9 \mathrm{mil}$ & 3.8 menit \\
\hline Water $\rightarrow$ Bradford & $4.1 \mathrm{mil}$ & 8.2 menit \\
\hline Bradford $\rightarrow$ Naperville F.D. & $5.5 \mathrm{mil}$ & 11 menit \\
\hline FD001 $\rightarrow$ FI046 $\rightarrow$ FI043 $\rightarrow$ FI047 $\rightarrow$ FI048 $\rightarrow$ FI0204 $\rightarrow$ FD001 & $19.5 \mathrm{mil}$ & 39 menit \\
\hline Kasus 2, Kejadian Kebakaran pada : 22 April 2019 & & \\
\hline Naperville F.D. $\rightarrow$ Rosecroft & $1 \mathrm{mil}$ & 2 menit \\
\hline Rosecroft $\rightarrow$ Normandy & $1.1 \mathrm{mil}$ & 2.2 menit \\
\hline Normandy $\rightarrow$ Bradford & $6.5 \mathrm{mil}$ & 13 menit \\
\hline Bradford $\rightarrow$ Audubon & $2.3 \mathrm{mil}$ & 4.6 menit \\
\hline Audubon $\rightarrow$ Naperville Wheaton & $6.1 \mathrm{mil}$ & 12.2 menit \\
\hline
\end{tabular}

Penentuan Rute Evakuasi Bencana Kebakaran Menggunakan Algoritma Dijkstra berbasis Web Framework Vue.js (I Gede Surya Rahayuda) 


\begin{tabular}{|c|c|c|}
\hline Rute Hasil & Jarak & Waktu \\
\hline Naperville Wheaton $\rightarrow$ Naperville F.D. & 9.6 mil & 19.2 menit \\
\hline $\mathrm{FD} 001 \rightarrow \mathrm{FI031} \rightarrow \mathrm{FI025} \rightarrow \mathrm{FI004} \rightarrow \mathrm{FI001} \rightarrow$ FI024 $\rightarrow$ FD001 & $26.6 \mathrm{mil}$ & 53.2 menit \\
\hline Kasus 3, Kejadian Kebakaran pada : 21 April 2019 & & \\
\hline Naperville F.D $\rightarrow$ Fulham & $1.6 \mathrm{mil}$ & 3.2 menit \\
\hline Fulham $\rightarrow$ Main & $6.3 \mathrm{mil}$ & 12.6 menit \\
\hline Main $\rightarrow$ Ogden & $1.7 \mathrm{mil}$ & 3.4 menit \\
\hline Ogden $\rightarrow$ Iroquois & $1.0 \mathrm{mil}$ & 2.0 menit \\
\hline Iroquois $\rightarrow$ Diehl & $5.7 \mathrm{mil}$ & 11.4 menit \\
\hline Diehl $\rightarrow$ Naperville F.D & $6.8 \mathrm{mil}$ & 13.6 menit \\
\hline $\mathrm{FD} 001 \rightarrow \mathrm{FI042} \rightarrow \mathrm{FI} 045 \rightarrow$ FI027 $\rightarrow$ FI044 $\rightarrow$ FI013 $\rightarrow$ FD001 & $23.1 \mathrm{mil}$ & 46.2 menit \\
\hline $4 \quad$ Kasus 4, Kejadian Kebakaran pada : 21 April 2019 & & \\
\hline Naperville F. D. $\rightarrow$ Grommon & $2.5 \mathrm{mil}$ & 5 menit \\
\hline Grommon $\rightarrow$ Flat Rock & 1.6 mil & 3.2 menit \\
\hline Flat Rock $\rightarrow$ Ogden & $7.7 \mathrm{mil}$ & 15.4 menit \\
\hline Ogden $\rightarrow$ Cantera & 4 mil & 8 menit \\
\hline Cantera $\rightarrow$ Naper & $3.7 \mathrm{mil}$ & 7.4 menit \\
\hline Naper $\rightarrow$ Naperville F. D. & $11.8 \mathrm{mil}$ & 23.6 menit \\
\hline FD001 $\rightarrow$ FI019 $\rightarrow$ FI016 $\rightarrow$ FI027 $\rightarrow$ FI008 $\rightarrow$ FI023 $\rightarrow$ FD001 & $31.3 \mathrm{mil}$ & 62.6 menit \\
\hline $\begin{array}{ll}5 & \text { Kasus 5, Kejadian Kebakaran pada : } 20 \text { April } 2019\end{array}$ & & \\
\hline Naperville F. D. $\rightarrow$ Willow Ridge & $1.9 \mathrm{mil}$ & 3.8 menit \\
\hline Willow Ridge $\rightarrow$ Buttonwood & 4 mil & 8 menit \\
\hline Buttonwood $\rightarrow$ Candlenut & 1.4 mil & 2.8 menit \\
\hline Candlenut $\rightarrow$ Westminster & $2.4 \mathrm{mil}$ & 4.8 menit \\
\hline Westminster $\rightarrow$ Diehl & $1.2 \mathrm{mil}$ & 2.4 menit \\
\hline Diehl $\rightarrow$ Naperville F. D. & $6.8 \mathrm{mil}$ & 13.6 menit \\
\hline FD001 $\rightarrow$ FI038 $\rightarrow$ FI006 $\rightarrow$ FI007 $\rightarrow$ FI036 $\rightarrow$ FI013 $\rightarrow$ FD001 & 17.7 mil & 35.4 menit \\
\hline Kasus 6, Kejadian Kebakaran pada : 19 April 2019 & & \\
\hline Naperville F. D. $\rightarrow$ Stockton & $1.7 \mathrm{mil}$ & 3.4 menit \\
\hline Stockton $\rightarrow$ White Eagle & $1.1 \mathrm{mil}$ & 2.2 menit \\
\hline White Eagle $\rightarrow$ Redstart & $5.7 \mathrm{mil}$ & 11.4 menit \\
\hline Redstart $\rightarrow$ Centre Point & $5.8 \mathrm{mil}$ & 11.6 menit \\
\hline Centre Point $\rightarrow$ Country Lakes & $4.5 \mathrm{mil}$ & 9 menit \\
\hline Country Lakes $\rightarrow$ Naperville F. D. & $6.8 \mathrm{mil}$ & 13.6 menit \\
\hline $\mathrm{FD} 001 \rightarrow \mathrm{FI034} \rightarrow \mathrm{FI037} \rightarrow \mathrm{FI030} \rightarrow \mathrm{FI010} \rightarrow$ FI011 $\rightarrow$ FD001 & 25.6 mil & 51.2 menit \\
\hline $\begin{array}{ll}7 & \text { Kasus 7, Kejadian Kebakaran pada : } 18 \text { April } 2019\end{array}$ & & \\
\hline Naperville F. D. $\rightarrow$ Aurora & 4.4 mil & 8.8 menit \\
\hline Aurora $\rightarrow$ Ellsworth & $3.3 \mathrm{mil}$ & 6.6 menit \\
\hline Ellsworth $\rightarrow$ Hobson Mill & $2.7 \mathrm{mil}$ & 5.4 menit \\
\hline Hobson Mill $\rightarrow$ Russet & $2.2 \mathrm{mil}$ & 4.4 menit \\
\hline Russet $\rightarrow$ Woodview & $2.2 \mathrm{mil}$ & 4.4 menit \\
\hline Woodview $\rightarrow$ Naperville F. D. & 5 mil & 10 menit \\
\hline $\mathrm{FD} 001 \rightarrow \mathrm{FI002} \rightarrow \mathrm{FI015} \rightarrow \mathrm{FI022} \rightarrow \mathrm{FI032} \rightarrow$ FI039 $\rightarrow$ FD001 & $19.8 \mathrm{mil}$ & 39.6 menit \\
\hline Kasus 8, Kejadian Kebakaran pada : 17 April 2019 & & \\
\hline Naperville F. D. $\rightarrow$ Dorval & $4.4 \mathrm{mil}$ & 8.8 menit \\
\hline Dorval $\rightarrow$ Washington & $1.5 \mathrm{mil}$ & 3 menit \\
\hline Washington $\rightarrow$ North & 5 mil & 10 menit \\
\hline WNorth $\rightarrow$ Patriots & $3.7 \mathrm{mil}$ & 7.4 menit \\
\hline Patriots $\rightarrow$ Genesee & $1.4 \mathrm{mil}$ & 2.8 menit \\
\hline Genesee $\rightarrow$ Naperville F. D. & 6.4 mil & 12.8 menit \\
\hline FD001 $\rightarrow$ FI014 $\rightarrow$ FI035 $\rightarrow$ FI026 $\rightarrow$ FI028 $\rightarrow$ FI018 $\rightarrow$ FD001 & $22.4 \mathrm{mil}$ & 44.8 menit \\
\hline Kasus 9, Kejadian Kebakaran pada : 16 April 2019 & & \\
\hline Naperville F. D. $\rightarrow$ Gypsum & $1 \mathrm{mil}$ & 2 menit \\
\hline Gypsum $\rightarrow$ Garnette & $3.7 \mathrm{mil}$ & 7.4 menit \\
\hline Garnette $\rightarrow$ Raintree & $4.5 \mathrm{mil}$ & 9 menit \\
\hline Raintree $\rightarrow$ Brookdale & $3.8 \mathrm{mil}$ & 7.6 menit \\
\hline Brookdale $\rightarrow$ Naperville Wheaton & $5.5 \mathrm{mil}$ & 11 menit \\
\hline Naperville Wheaton $\rightarrow$ Naperville F. D. & 9.6 mil & 19.2 menit \\
\hline FD001 $\rightarrow$ FI020 $\rightarrow$ FI017 $\rightarrow$ FI029 $\rightarrow$ FI005 $\rightarrow$ FI024 $\rightarrow$ FD001 & $28.1 \mathrm{mil}$ & 56.2 menit \\
\hline $10 \quad$ Kasus 10, Kejadian Kebakaran pada : 15 April 2019 & & \\
\hline Naperville F. D. $\rightarrow$ Spartina & $3.3 \mathrm{mil}$ & 6.6 menit \\
\hline Spartina $\rightarrow$ Harbor & $7.8 \mathrm{mil}$ & 15.6 menit \\
\hline Harbor $\rightarrow$ Center & $3.4 \mathrm{mil}$ & 6.8 menit \\
\hline Center $\rightarrow$ Crystal & $3.9 \mathrm{mil}$ & 7.8 menit \\
\hline Crystal $\rightarrow$ Bond & $1.1 \mathrm{mil}$ & 2.2 menit \\
\hline Bond $\rightarrow$ Naperville F. D. & $6.1 \mathrm{mil}$ & 12.2 menit \\
\hline FD001 $\rightarrow$ FI033 $\rightarrow$ FI021 $\rightarrow$ FI009 $\rightarrow$ FI012 $\rightarrow$ FI003 $\rightarrow$ FD001 & $25.6 \mathrm{mil}$ & 51.2 menit \\
\hline
\end{tabular}


Tabel 3. Perbandingan hasil Algoritma Dijkstra dan Held-Karp.

\begin{tabular}{lrr}
\hline & Dijkstra & Held-Karp \\
\hline Kasus 1 & $19.5 \mathrm{mil}$ & $17.8 \mathrm{mil}$ \\
\hline Kasus 2 & $26.6 \mathrm{mil}$ & $26.2 \mathrm{mil}$ \\
\hline Kasus 3 & $23.1 \mathrm{mil}$ & $23.1 \mathrm{mil}$ \\
\hline Kasus 4 & $28 \mathrm{mil}$ & $31.3 \mathrm{mil}$ \\
\hline Kasus 5 & $17.7 \mathrm{mil}$ & $17.7 \mathrm{mil}$ \\
\hline Kasus 6 & $25.6 \mathrm{mil}$ & $24.8 \mathrm{mil}$ \\
\hline Kasus 7 & $19.8 \mathrm{mil}$ & $19.8 \mathrm{mil}$ \\
\hline Kasus 8 & $22.4 \mathrm{mil}$ & $20.9 \mathrm{mil}$ \\
\hline Kasus 9 & $28.1 \mathrm{mil}$ & $25.5 \mathrm{mil}$ \\
\hline Kasus 10 & $25.6 \mathrm{mil}$ & $25.6 \mathrm{mil}$ \\
\hline
\end{tabular}

Selain metode Dijkstra, penulis juga melengkapi halaman web dengan beberapa halaman, dimana pada tiap halaman menampilkan kelebihan dari framework Vue.js. Halaman Home merupakan halaman pertama yang diakses oleh user, pada halaman Home terdapat sidebar yang berisikan carousel dari gambar yang ada. Pada main content terdapat timeline yang berisikan berita atau posting-an yang dibuat oleh admin. Timeline dibuat menggunakan Vuetify.js, saat kursor diarahkan pada salah satu posting-an maka secara otomatis akan menutup gambar dan memfokuskan pada tombol detail dan tulisan. Pada halaman ini juga terdapat menu navigation yang mengarahkan pada semua halaman. Halaman Fire Incident berisikan semua informasi mengenai lokasi kejadian kebakaran yang pernah terjadi pada kota Napperville. Pada tabel terdapat tanggal, alamat, dan besar kerusakan yang terjadi menggunakan progress bar. Penyebab terjadinya kebakaran ditampilkan menggunakan tooltip yang akan muncul jika kursor diarahkan pada progress bar. Halaman Fire Station merupakan halaman yang berisi semua data mengenai fire station yang ada di kota Naperville, list fire station dibuat menggunakan card deck. Halaman Contact Us merupakan halaman yang dibangun agar user yang mengakses website dapat meng-input-kan data berupa biodata dan pertanyaan mengenai bencana kebakaran, departemen dan masalah atau keluhan lainnya. Data pertanyaan yang telah disimpan pada halaman Contact Us dapat diakses melalui halaman Question. Jika tombol View All ditekan, maka secara otomatis semua pertanyaan akan ditampilkan satu persatu sampai batas queue maksimal kemudian hilang atau dеqиеие dan digantikan oleh pertanyaan lainnya atau enquеие dan begitu seterusnya, sehingga pertanyaan tersebut terlihat terus bergerak. Proses tersebut atau disebut dengan realtime loging dibangun menggunakan material desain vuetify.js. Selain menggunakan media komputer atau laptop, tentunya website juga akan diakses menggunakan device lainnya yang lebih kecil seperti tab dan handphone. Website yang dibangun sudah menerapkan teknologi responsive, sehingga jika diakses menggunakan halaman kecil website akan tetap menyesuaikan dengan tampilan layar.

\subsection{Pengujian Sistem}

Pada penelitian ini digunakan metode pengujian black box testing. Pengujian dilakukan dengan menguji bagian antarmuka dari sistem informasi, setiap bagian dari antarmuka tersebut diuji agar dapat ditentukan apakah sistem sudah berjalan sesuai dengan fungsi yang diharapkan [8]. Tujuan dari pengujian ini adalah untuk mengetahui kesalahan pada sistem yang dibuat. Berikut adalah hasil pengujian menggunakan metode black box testing yang ditampilkan dalam bentuk tabel:

Tabel 4. Hasil pengujian sistem.

\begin{tabular}{|c|c|c|c|}
\hline No & Kelas Uji & Skenario Pengujian & Hasil Pengujian \\
\hline 1 & Halaman Home & $\begin{array}{l}\text { Admin atau user dapat mengakses halaman home, pada halaman } \\
\text { home akan menampilakn beberapa konten berita yang ditampilkan } \\
\text { dalam bentuk timeline, setiap kolom berita dapat ditekan agar } \\
\text { selanjutnya dapat diakses halaman yang menampilkan detail berita }\end{array}$ & Sesuai \\
\hline 2 & Halaman Fire Incident & $\begin{array}{l}\text { Halaman fire incident dapat diakses oleh admin dan user, halaman } \\
\text { tersebut akan menampilkan list semua lokasi bencana kebakaran } \\
\text { dalam bentuk tabel, terdapat kolom berupa persentase kerusakan } \\
\text { dalam bentuk barline, dimana apabila kursor diarahkan pada } \\
\text { barline akan menampilkan detail kerusakan dalam bentuk tooltips }\end{array}$ & Sesuai \\
\hline 3 & Halaman Fire Stations & $\begin{array}{l}\text { Halaman fire stations dapat diakses oleh user dan admin, halaman } \\
\text { tersebut akan menampilkan semua stasiun pemadam yang ada } \\
\text { dalam bentuk card column yang disertai dengan gambar }\end{array}$ & Sesuai \\
\hline 4 & Halaman Dijkstra & $\begin{array}{l}\text { Halaman Dijkstra merupakan halaman utama dari sistem, dimana } \\
\text { admin dapat mengakses dan dapat menginputkan tempat kejadian } \\
\text { bencana kebakaran, jika ditekan tombol submit maka sistem akan } \\
\text { memproses graph matriks dan metode Dijkstra untuk mendapatkan } \\
\text { solusi rute terbaik }\end{array}$ & Sesuai \\
\hline
\end{tabular}

Penentuan Rute Evakuasi Bencana Kebakaran Menggunakan Algoritma Dijkstra berbasis Web Framework Vue.js (I Gede Surya Rahayuda) 


\begin{tabular}{cclc}
\hline No & \multicolumn{1}{c}{ Kelas Uji } & \multicolumn{1}{c}{ Skenario Pengujian } & Hasil Pengujian \\
\hline 5 & Halaman Halaman Contact & $\begin{array}{l}\text { Halaman } \text { contact } \text { us dapat diakses oleh } \text { user, } \text { user dapat } \\
\text { menginputkan identitas dan dapat menuliskan saran atau pertanyaan } \\
\text { kemudian data tersebut akan disimpan pada basis data sistem }\end{array}$ & Sesuai \\
& & Halaman questions dapat diakses oleh user dan admin, pada \\
halaman ini digunakan teknologi realtime logging dari vuetify.js, \\
dimana jika tombol view questions ditekan, maka semua pertanyaan \\
yang ada pada database akan ditampilkan dalam bentuk animasi \\
\end{tabular}

\section{Kesimpulan}

Sistem informasi penentuan rute evakuasi bencana kebakaran telah berhasil dikembangkan menggunakan framework vue.js. Alur dan desain sistem berhasil di ilustrasikan menggunakan data flow diagram, dimana data flow diagram dikembangkan hingga level 2. Metode Dijkstra berhasil diterapkan pada sistem dan berhasil diujicobakan pada beberapa data tes. Namun terdapat beberapa kegagalan pada perbandingan hasil dari ujicoba algoritma Dijkstra dan Held-Karp terhadap data yang sama. Dari 10 kasus kejadian kebakaran, terdapat sebanyak 4 kasus evakuasi yang memiliki hasil sama antara metode Dijkstra dan Held-Karp dan terdapat 6 kasus evakuasi, dimana metode Held-Karp memiliki hasil yang lebih baik dibandingkan dengan metode Dijkstra. Hal ini mungkin disebabkan karena metode Dijkstra diterapkan pada kasus yang mengunjungi semua titik dan memungkinkan perjalanan kembali ke titik awal. Keterbatasan jumlah data uji juga dapat mempengaruhi hasil. Pengujian sistem dilakukan menggunakan metode black box testing, berdasarkan hasil dari pengujian didapatkan hasil yang baik dan sesuai dengan keinginan.

\section{Daftar Pustaka}

[1] I. G. S. Rahayuda and N. P. L. Santiari, "Penerapan Pemrograman Dinamis Pada Manajemen Pengiriman Produk Menggunakan Metode Held-Karp," in Konferensi Nasional Sistem \& Informatika 2017, 2017, pp. 513-518.

[2] I. G. S. Rahayuda and N. P. L. Santiari, "Implementasi dan Perbandingan Metode Iterative Deepening Search dan Held-Karp pada Manajemen Pengiriman Produk," J. Sisfo Inspirasi Prof. Sist. Inf. Iinstitut Teknol. Sepuluh Nop., vol. 07, no. 02, 2017.

[3] I. G. S. Rahayuda and N. P. L. Santiari, "Basis Path Testing of Iterative Deepening Search and HeldKarp on Pathfinding Algorithm," J. Ilm. Kursor, vol. 9, no. 2, 2018.

[4] I. G. S. Rahayuda, N. P. L. Santiari, and N. Y. Arso, "Penerapan Bidirectional Search Dan Held-Karp Pada Penentuan Rute Pengiriman Produk," J. Teknol. Inf. dan Ilmu Komput., vol. 5, no. 5, pp. 549558, 2018.

[5] I. G. S. Rahayuda and N. P. L. Santiari, "Penerapan Algoritma Depth Limited Search pada Penentuan Rute Pengiriman Produk," in Seminar Nasional Telekomunikasi dan Informatika (Selisik) 2018, 2018, pp. $184-189$.

[6] I. G. S. Rahayuda and N. P. L. Santiari, "Fire Incident Emergency Response Plan using Hybrid Fuzzy Dijkstra," 2019 1st Int. Conf. Cybern. Intell. Syst., 2019.

[7] I. G. S. Rahayuda and N. P. L. Santiari, "Penentuan Rute Evakuasi Bencana Kebakaran Menggunakan Metode Dijkstra," in Seminar Nasional Pendidikan Teknik Informatika (SENAPATI) ke-10 Tahun 2019, 2019.

[8] N. L. P. S. Aditya Herdinata Putra, Dian Pramana, "Sistem Manajemen Arsip Menggunakan Framework Laravel dan Vue.Js (Studi Kasus : BPKAD Provinsi Bali)," J. Sist. dan Inform., vol. 13, no. 2, 2019.

[9] H. X. Junhui Song, Min Zhang, "Design and Implementation of a Vue.js-Based College Teaching System," Int. J. Emerg. Technol. Learn., vol. 14, no. 13, 2019.

[10] Y. Quan, "Design and Implementation of E-commerce Platform based on Vue.js and MySQL," in Proceedings of the 3rd International Conference on Computer Engineering, Information Science \& Application Technology (ICCIA 2019), 2019.

[11] M. Krumova, "Open Data Benchmarking for Higher Education: Management and Technology Perspectives," Smart Cities Reg. Dev. J., 2017.

[12] A. W. Sejati, "Pemanfaatan Open Data untuk Mencari Jurnal dan Referensi Ilmiah," Res. Gate, 2019.

[13] C. Kure, "Open Data in a Big Data World," Sci. Int., 2015.

[14] A. Z. Marijn Janssen, Yannis Charalabidis, "Benefits, Adoption Barriers and Myths of Open Data and Open Government,” J. Inf. Syst. Manag., vol. 29, 2012. 